Journal of Clinical Investigation

Vol. 41, No. 9, 1962

\title{
ACCELERATED TURNOVER OF PHOSPHORIBOSYLPYROPHOSPHATE, A PURINE NUCLEOTIDE PRECURSOR, IN CERTAIN GOUTY SUBJECTS *
}

\author{
By OLIVER W. JONES, JR., $†$ DORIS M. ASHTON AND JAMES B. WYNGAARDEN \\ (From the Departments of Medicine and Biochemistry, Duke University Medical Center, \\ Durham, N. C.)
}

(Submitted for publication January 18, 1962; accepted June 7, 1962)

Existing tracer studies on the metabolic defect of primary gout have employed injection of labeled uric acid and measurement of the kinetic behavior of the uric acid pool by classical dilution technics $(3,4)$, or administration of a labeled precursor and measurement of its incorporation into uric acid $(5,6,7,8)$. The dilution studies have shown major increases in the miscible pool of uric acid in almost all gouty subjects studied. The incorporation studies have consistently demonstrated unequivocal abnormalities of uric acid production only in those gouty patients showing excessive basal urinary excretions of uric acid, a subgroup estimated to represent about 28 per cent of the gouty population (9). In the larger subgroup of gouty patients with normal basal urinary excretions of uric acid, abnormalities of turnover of uric acid or of incorporation of labeled precursor into uric acid have been encountered in only about one-half of the subjects studied (10). These abnormalities have frequently been of less decisive degree and at times have been demonstrable only after appropriate corrections have been applied for the greater extrarenal disposal and greater dilution of newly formed labeled uric acid found in gouty patients than in controls (11). In addition, subjects of both subgroups have shown abnormalities of intramolecular distribution of $\mathrm{N}^{15}$ in uric acid after administration of $\mathrm{N}^{15} \mathrm{H}_{4} \mathrm{Cl}$ or of glycine $\mathrm{N}^{15}$ (12). The metabolic abnormalities encountered are consistent with a defective regulatory mechanism of purine synthesis de novo in the overexcretor gouty subject and possibly of more subtle degree in the normal excretor gouty subject also.

Data on labeling of urinary purine bases after oral administration of glycine $1-\mathrm{C}^{14}$ gave sugges-

* Supported in part by grant A-1391 from the U. S. Public Health Service. Preliminary reports of this work have appeared $(1,2)$.

† Present address: National Institute of Arthritis and Metabolic Diseases, Bethesda, Maryland. tive evidence that the pathways of excessive uric acid synthesis in gout involved the same purine nucleotide intermediates as in normal subjects (13). When subsequently a potential feedback regulatory mechanism of purine synthesis was discovered in which the first specific step of purine synthesis was found to be controlled by adenyl ribonucleotides such as ADP and ATP (14), it was suggested that a defect of this regulatory mechanism might explain the metabolic aberrations of gout (10). The biochemical step in question is that in which 5- $\alpha$-phosphoribosyl-1-pyrophosphate (PRPP) and glutamine react to form 5 - $\beta$-phosphoribosyl-1-amine (15), the first unique and obligatory precursor of purine ribonucleotides. Hence, a necessary concomitant of a derangement of this feedback control mechanism would be an increase in turnover of PRPP and glutamine in patients showing accelerations of uric acid synthesis de novo.

Recently a second reaction has been described by which phosphoribosylamine may be formed. In this reaction ribose 5-phosphate and ammonia interact directly to form phosphoribosylamine without the intermediary formation of PRPP (16). It was first thought that this reaction was catalyzed by a specific enzyme. The reaction has now been shown to occur nonenzymatically (17).

For many reasons, therefore, it appeared interesting to investigate the role of PRPP in purine synthesis in gouty subjects. Among them is the desirability of appraising the results of previous studies which have included the end product, uric acid, by an independent method involving an early precursor of purines. The present paper reports an indirect approach toward study of the metabolic turnover of PRPP, based upon prior observations of other workers $(18,19)$. The approach is that of labeling PRPP by oral administration of glucose $\mathrm{U}-\mathrm{C}^{14}$ and of trapping a portion of the PRPP by concomitant administration of 
imidazoleacetic acid (IAA), a natural metabolite of histidine which is converted to its ribonucleotide derivative by reaction with PRPP (20) and is subsequently excreted in urine as an isolable product, imidazoleacetic acid ribonucleoside (IAAR) (21).

\section{MATERIALS AND METHODS}

Imidazoleacetic acid hydrochloride was synthesized from DL-histidine hydrochloride according to Bauer and Tabor (22). The hydrochloride was removed by passage of the compound through Dowex-1-acetate (23). ${ }^{1}$ Imidazoleacetic acid ribonucleoside, $90 \mathrm{mg},{ }^{2}$ was tritiated by the Wilzbach procedure at the New England Nuclear Corporation, Boston. This material was purified by sequential chromatography on Dowex-1-acetate and Dowex 50 -hydrogen resins, and on paper in $t$-butanol-formic acid $-\mathrm{H}_{2} \mathrm{O}$, and finally by paper electrophoresis for 1.5 hours at $900 \mathrm{v}$ in $0.025 \mathrm{M}$ phosphate, $\mathrm{pH} 6.5$ (18). The IAAR $-\mathrm{H}^{3}$ recovered from paper after electrophoresis migrated as authentic IAAR in parallel and mixed paper chromatograms in several solvent systems (18). Final yield was 7 per cent of material exposed to tritium gas, and the specific activity of IAAR- $\mathrm{H}^{3}$ was $0.96 \mathrm{mc}$ per $\mathrm{mg}$. Hydrolysis with bacterial hydrolase showed 27.4 per cent of the total $\mathrm{H}^{3}$ to be in the ribose moiety of IAAR. Glucose $\mathrm{C}^{14}$, uniformly labeled, $4 \mathrm{mc}$ per mmole, was obtained commercially. ${ }^{3} \quad \beta$-Riboside hydrolase was prepared from $L$. delbrueckii 9649,4 according to Takagi and Horecker (24) through stage IV (the 50 to 80 per cent ammonium sulfate fraction). Xanthine oxidase of high specific activity, 15 to $16 \mathrm{U}$ per $\mathrm{mg}$ of protein (25), required for assay of hydrolase activity, was prepared by submitting the commercial enzyme, $2 \pm U$ per $\mathrm{mg}^{5}$ to chromatography on an hydroxyapatite column (26) according to the method of Carey, Fridovich and Handler (27). Uricase ${ }^{5}$ was employed in the determination of uric acid in serum and urine by differential ultraviolet spectrophotometry (28).

Subjects. The subjects studied included seven control and nine gouty subjects, all males (see Table I). The control subjects were patients hospitalized for study of mild illness, who gave no personal or familial history of gout and who were found to have normal serum and 24hour urinary uric acid values. The gouty subjects included three with elevated 24-hour urinary uric acid excretion values and six with normal 24-hour excretion values, as defined by Gutman and Yü (9). All gave his-

\footnotetext{
1 In later experiments imidazoleacetic acid was purchased from California Corporation for Biochemical Research.

2 Obtained as a gift from Dr. G. A. Jamieson and Dr. Herbert Tabor of NIH, Bethesda, Md.

3 Volk Radiochemicals, Chicago.

4 Obtained from American Type Culture Collection.

5 Purchased from Worthington Biochemical Corporation, Freehold, N.J.
}

tories of typical colchicine-responsive attacks of acute gout, except for one hyperuricemic member of a gouty family who was asymptomatic prior to study (J.E., Jr., Table I) but who has since experienced a colchicine-responsive gouty attack. The studies on J.E., Jr., and J.E., Sr., and the second study on J.B. were conducted while they received uricosuric drugs. Serum and urinary uric acid values had been obtained on these patients prior to the beginning of therapy.

Experimental procedure. All subjects avoided purinerich foods for 2 to 3 days prior to the study. After an overnight fast each subject received $18 \mu$ moles per $\mathrm{kg}$ of IAA together with an equivalent amount of $\mathrm{NaHCO}_{3}$ in water orally. Immediately thereafter he was also given 15 to $25 \mu \mathrm{c}$ of glucose $\mathrm{U}-\mathrm{C}^{14}$ in water orally. (All results were subsequently normalized to an administered dose of $20 \times 10^{\circ} \mathrm{cpm}$.) Two hours later he was permitted to eat a normal breakfast and to resume normal hospital ward activity. Urine was collected either in five consecutive 2-hour samples or in a single 10-hour sample, each in $5 \mathrm{ml}$ of glacial acetic acid. IAAR was then isolated from one-third of this urine sample according to Hiatt $(19,21)$ by employing Dowex-1-acetate $\times 4,100$ 200 mesh, in columns containing resin beds $20 \mathrm{~cm}$ in height and $4.5 \mathrm{~cm}$ in diameter. Initially, IAAR was located in the 200 to $600 \mathrm{ml}$ fractions of the $0.2 \mathrm{~N}$ acetic acid eluate by release of an orcinol reactive substance from an aliquot after hydrolysis with bacterial $\beta$-riboside hydrolase. In later experiments the position of IAAR in the eluate was located by employing a small quantity of IAAR- $\mathrm{H}^{3}$ as a marker. IAAR- $\mathrm{H}^{3}, 25,000$ counts, was added to the urine sample before adsorption onto Dowex1-acetate resin, the $\mathrm{H}^{3}$ peak located in the eluate, and IAAR analyzed in this fraction. In paired experiments the results were the same, but use of the tritiated marker shortened the procedure and permitted greater precision in selection of appropriate eluates for further analysis. (The concentrations of IAAR in the eluates are too low to permit localization by orcinol or periodate tests without preliminary reductions of volume of individual samples.)

The eluates from the Dowex-1-acetate column which contained IAAR were reduced to dryness at $30^{\circ}$ in a flash evaporator, redissolved in $5 \mathrm{ml}$ of water, and placed on Dowex 50-hydrogen $\times 8,200-400$ mesh, in a column containing a resin bed $8 \mathrm{~cm}$ in height and $1.0 \mathrm{~cm}$ in diameter. The IAAR was eluted by gradient elution (21). The separatory funnel reservoir contained $250 \mathrm{ml}$ of $\mathrm{H}_{2} \mathrm{O}$ and into this flowed $2 \mathrm{~N} \mathrm{HCl}$. IAAR appeared in the 100 to $200-\mathrm{ml}$ eluate.

The fractions containing IAAR were pooled, reduced to dryness in vacuo at $30^{\circ} \mathrm{C}$, dissolved in water, and buffered to $\mathrm{pH} 6.0$ with citrate buffer, ${ }^{\prime} 0.05 \mathrm{M}$; the IAAR was then hydrolyzed for 6 hours at $38^{\circ} \mathrm{C}$ with freshly prepared bacterial enzyme. ${ }^{\circ}$ The reaction was stopped

6 A minimum of $1.0 \mathrm{U}$ of enzyme activity per $\mathrm{mg}$ of IAAR-ribose was employed, since this ratio of enzyme activity to IAAR was found to give quantitative hydrolysis in 4 to 5 hours. If the final yield of ribose indicated 
TABLE I

Data on subjects of the present study

\begin{tabular}{|c|c|c|c|c|c|c|c|c|}
\hline \multirow[b]{2}{*}{ Subject } & \multirow[b]{2}{*}{ Age } & \multirow[b]{2}{*}{ Weight } & \multicolumn{2}{|c|}{ Uric acid } & \multirow[b]{2}{*}{ Excretion of IAAR } & \multirow[b]{2}{*}{ C14 in IAAR } & \multirow{2}{*}{$\begin{array}{l}\text { Specific } \\
\text { activity } \\
\text { of IAAR }\end{array}$} & \multirow[b]{2}{*}{ Comment } \\
\hline & & & Serum* & Urinet & & & & \\
\hline & yrs & kg & $m g \%$ & $m g / 24 h r$ & \% of administered & $\begin{array}{l}\% \text { of administered } \\
\text { glucose } U-C^{14}\end{array}$ & $\underset{\text { ribose }}{c p m / m g}$ & \\
\hline \multicolumn{9}{|c|}{ Control subjects } \\
\hline J.D. & 16 & 63.6 & 4.1 & 400 & 7.1 & 0.010 & 128 & Idiopathic epilepsy \\
\hline L.D. & 26 & 75.0 & 6.0 & 400 & 4.7 & 0.013 & 251 & $\begin{array}{l}\text { Inactive rheumatic heart dis- } \\
\text { ease, Class IA }\end{array}$ \\
\hline Jo.B. & 28 & 89.1 & 5.2 & 226 & 4.4 & 0.021 & 439 & $\begin{array}{l}\text { Emotional disturbance; BUN } \\
15 \mathrm{mg} \%\end{array}$ \\
\hline J.W. & 68 & 95.4 & 5.8 & 429 & 12.4 & 0.043 & 312 & Non-toxic goiter \\
\hline W.R. & 38 & 81.8 & 5.6 & 413 & 19.3 & 0.047 & 217 & $\begin{array}{l}\text { Inactive rheumatic heart dis- } \\
\text { ease, Class IA }\end{array}$ \\
\hline W.Y.8 & 32 & 81.8 & 6.5 & 629 & 21.6 & 0.074 & 306 & $\begin{array}{l}\text { Asymptomatic brother of gouty } \\
\text { subject J.Y. (below) }\end{array}$ \\
\hline R.G. & 24 & 70.0 & 4.7 & 475 & 12.5 & 0.057 & 484 & Normal college student \\
\hline \multicolumn{9}{|c|}{ Gouty subjects } \\
\hline J.E., Jr. & 15 & 61.4 & 11.4 & 287 & 10.0 & 0.012 & 127 & 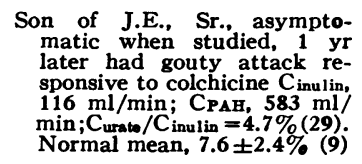 \\
\hline J.E., Sr. & 39 & 65.9 & 10.9 & 397 & 1.57 & 0.058 & 331 & $\begin{array}{l}\text { Severe tophaceous gout; PSP } \\
62 \% / 2 \text { hours }\end{array}$ \\
\hline H.H. & 50 & 110.0 & 9.8 & 685 & 15.4 & 0.164 & 950 & $\begin{array}{l}\text { Non-tophaceous gout, } 6 \text { yrs; } \\
\text { BUN } 16 \mathrm{mg} \% ; \text { PSP } 55 \% / 2 \\
\text { hrs; incorporated glycine } \\
1-C 14 \text { into uric acid excessively } \\
\text { (30) }\end{array}$ \\
\hline T.W. & 35 & 102.0 & 8.5 & 973 & 12.1 & 0.200 & 1104 & $\begin{array}{c}\text { Recurrent podagra, } 3 \text { yrs; BUN } \\
13 \mathrm{mg} \% ; \text { PSP } 68 \% / 2 \mathrm{hrs}\end{array}$ \\
\hline J.B. & 45 & 79.6 & 10.8 & 670 & 19.2 & 0.310 & 1220 & $\begin{array}{l}\text { Moderately severe tophaceous } \\
\text { gout; 7-yr history; BUN } 15 \\
\text { mg\%; PSP 45\%/2 hrs }\end{array}$ \\
\hline M.C. & 26 & 104.5 & 7.4 & 588 & 14.4 & 0.019 & 120 & $\begin{array}{l}\text { One attack of podagra, respond- } \\
\text { ing dramatically to colchicine }\end{array}$ \\
\hline J.Y. & 36 & 84.1 & 10.5 & 292 & 14.3 & 0.062 & 387 & Typical gout attacks, 7 yrs \\
\hline L.E. & 36 & 90.0 & 10.0 & 352 & 7.3 & 0.019 & 242 & Typical gout attacks, 6 yrs \\
\hline J.L. & 45 & 57.8 & 10.9 & 360 & 12.9 & 0.040 & 402 & $\begin{array}{l}\text { Three typical attacks of poda- } \\
\text { gra, responding to colchicine, } \\
\text { in previous year. Carcinoma } \\
\text { of colon, loss of } 10 \mathrm{~kg}\end{array}$ \\
\hline
\end{tabular}

* Normal range, enzymatic method, $5.1 \pm 1.0 \mathrm{mg} \%$ (31).

+ Normal range, $418 \pm 70 \mathrm{mg} / 24$ hours (9).

Abbreviations: BUN =blood urea nitrogen; PSP = phenolsulfonephthalein

W.Y. is considered a control subject because his serum uric acid level falls within the normal range and he has had no symptoms suggestive of gout. He is, however, a member of a gouty family, and his 24 -hour uric acid excretion value (single sample) is elevated. In any event, his

with perchloric acid, $\mathrm{KClO}_{4}$ removed from the neutralized chilled filtrate, and the supernatant solution then passed through a mixed-bed resin, ${ }^{7}$ according to Hiatt (21). The eluates and washings were pooled and reduced in volume. Aliquots were then analyzed for ribose according to Albaum and Umbreit (32) and for $\mathrm{C}^{14}$ in ethanol-toluene-PPO-POPOP (33) in a liquid scintillation spectrometer. Samples containing both $\mathrm{C}^{14}$ and $\mathrm{H}^{3}$ were counted at the optimal voltage for each isotope to permit calculation of the radioactivity attributable to each individually (34). All samples were subsequently recounted by employing an internal $\mathrm{C}^{14}$ standard to cor-

that a lower enzyme/IAAR ratio had been employed, another aliquot was hydrolyzed with more enzyme.

7 MB-3, Fisher Company. rect slightly variable quenching effects of the ions in the column eluates.

A number of control studies were performed to evaluate the specificity of procedures employed to isolate the ribose moiety of IAAR. The specific activity values of ribose were 50 to 132 per cent higher after rechromatography of the IAAR fraction on Dowex $50-\mathrm{H}^{+}$than in the initial eluate from Dowex-1-acetate column. The increments were comparable in control, gouty normal excretor and gouty overexcretor patients. The major additional ribose-containing compound in the Dowex-1-acetate column eluate was shown by spectral and paper chromatographic methods to be uridine, which was unlabeled in the 0 - to 10-hour period after glucose $U-C^{14}$ administration. Uridine was separated from IAAR on Dowex 


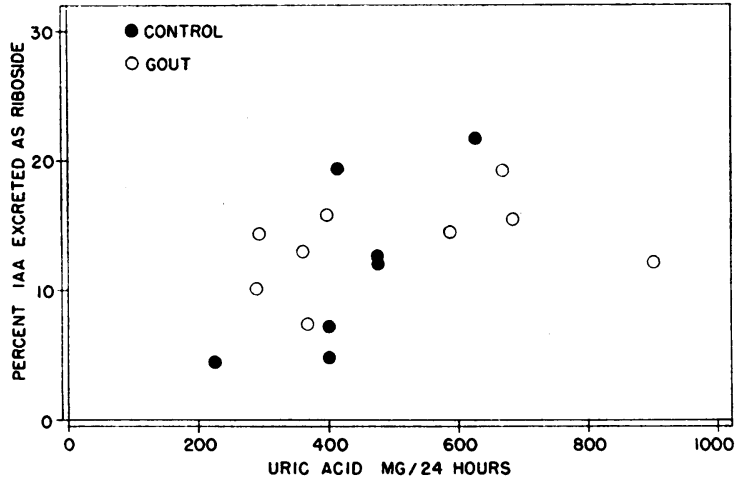

Fig. 1. ExCRETION OF IMIDAZOLEACETIC ACID RIBONUCLEOSIDE. The percentage of the test dose of imidazoleacetic acid excreted as the ribonucleoside derivative is plotted against the 24-hour urinary uric acid excretion for control and gouty subjects. The two values are not significantly correlated.

$50-\mathrm{H}^{+}$, together with some labeled compounds, more acidic than IAAR, which were not further identified.

In a few instances the IAAR fraction obtained from Dowex $50-\mathrm{H}^{+}$resin was reduced to dryness at $30^{\circ} \mathrm{C}$ in a flash evaporator, redissolved in water, and chromatographed on Whatman no. 1 paper by the descending method in isoamyl alcohol-phosphate buffer solvent (18). The IAAR was located by treating margin strips with periodate and benzidine (35). IAAR was eluted and hydrolyzed and the ribose recovered after passage through a mixed-bed resin. The specific activity of ribose was about 30 per cent higher after the additional paper chromatographic purification of IAAR, but this step was not employed routinely because of the losses of material encountered. The results reported in this paper are those obtained after hydrolysis of IAAR in the Dowex $50-\mathrm{H}^{+}$eluate. A second point, that of the purity of ribose- $\mathrm{C}^{14}$ obtained from the mixed-bed resin column, was evaluated in selected samples by subsequent paper chromatography of ribose in butanol-acetic acid- $\mathrm{H}_{2} \mathrm{O}$ (18). There was no change in the specific activity of ribose as a result of this additional procedure in the four samples studied and it also was not employed routinely. In paper chromatographic and electrophoretic work, IAA was located with diazotized p-nitroaniline (23) or diazotized sulfanilic acid (36), IAAR with periodate and benzidine (35), and ribose with aniline hydrogen phthalate (37).

\section{RESULTS}

Urinary excretion of imidazoleacetic acid ribonucleoside. The percentage of the test dose of IAA excreted as the ribonucleoside derivative in 10 hours in urine is listed in Table I and plotted for all subjects as a function of the 24-hour urinary uric acid excretion value in Figure 1. The values

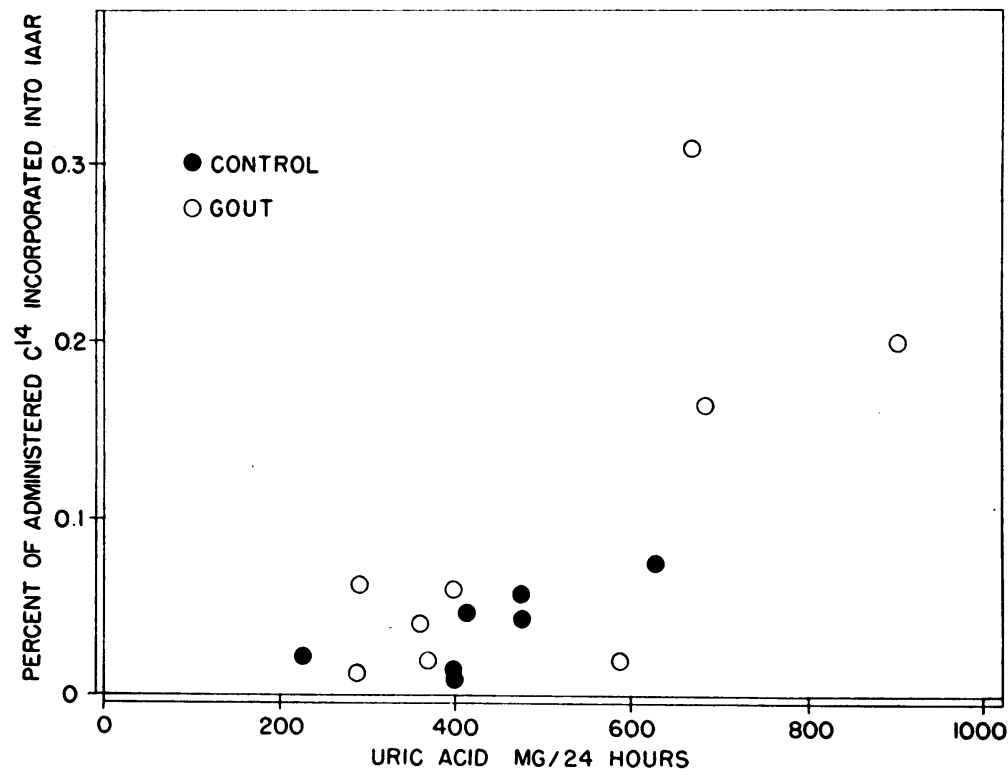

Fig. 2. INCORPORATION OF $\mathrm{C}^{14}$ INTO IMIDAZOLEACETIC ACID RIBONUCLEOSIDE. The percentage of the administered dose of glucose- $U-C^{14}$ incorporated into imidazoleacetic acid ribonucleoside and excreted in urine in 10 hours is plotted against the urinary uric acid excretion. Note the three gouty subjects who show both excessive incorporation of $\mathrm{C}^{14}$ and excessive excretion of uric acid. 
ranged from 4.4 to 21.6 per cent in seven control subjects (mean, $11.7 \pm 6.8$ per cent) and from 7.3 to 19.2 per cent in nine gouty subjects (mean, $13.5 \pm 3.4$ per cent). Among the gouty patients, the mean value of the six subjects with normal uric acid excretions was 12.4 per cent, and the mean value of the three subjects with excessive uric acid excretions was 15.6 per cent. None of these mean values is significantly different from the mean value of the control group. Furthermore, the positive correlation between the per cent of IAA excreted as IAAR and the 24-hour uric acid excretion in these 16 subjects was not statistically significant $(\mathrm{r}=+0.465, \mathrm{p}>0.05)$.

Incorporation of $C^{14}$ into urinary IAAR. The percentage of the administered dose of glucose $\mathrm{U}-\mathrm{C}^{14}$ appearing in urinary IAAR in 10 hours is listed in Table I and plotted in Figure 2 as a function of the uric acid excretion value of each subject. In the control subjects, incorporation values ranged from 0.010 to 0.074 per cent and in the gouty patients with normal uric acid excretions, from 0.012 to 0.062 per cent. In the three patients with clinical gout and excessive urinary uric acid excretion, the incorporation values were 0.164 , 0.200 , and 0.310 per cent. The values found in the gouty subjects with normal uric acid excre-

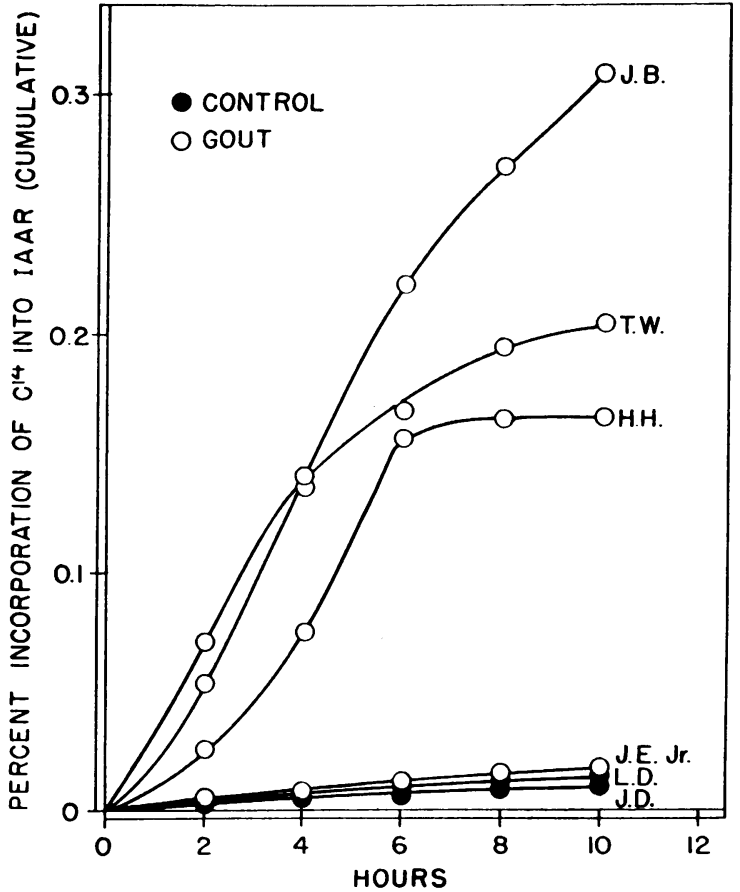

Fig. 3. Cumulative incorporation of $\mathrm{C}^{14}$ into imiDAZOLEACETIC ACID RIBONUCLEOSIDE. The cumulative incorporation of $\mathrm{C}^{14}$ into IAAR is presented for two control subjects, one gouty subject with a low normal value of uric acid excretion (J.E., Jr.), and three gouty subjects with excessive values of uric acid excretion (J.B., T.W., and H.H.).

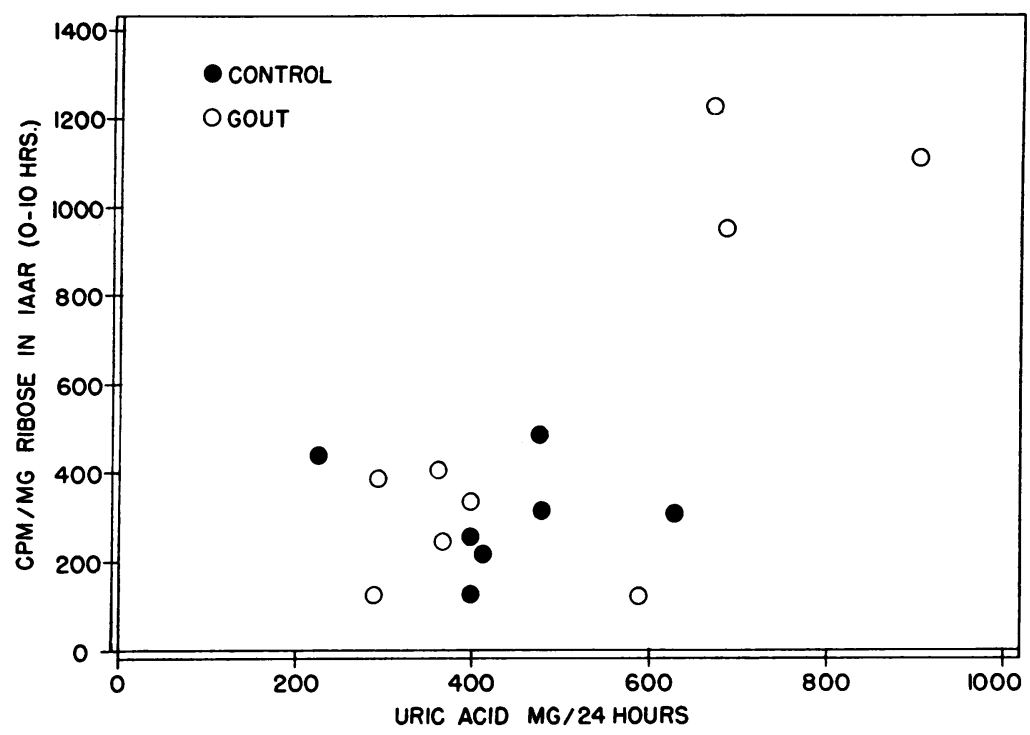

Fig. 4. SPECIFIC ACtivity OF THE RIBOSE MOIETy OF IMIDAZOLEACETIC ACID RIBONUCLEOSIDE. The specific activity value of the ribose moiety of IAAR during the 10-hour period after administration of IAA and glucose $\mathrm{U}-\mathrm{C}^{14}$ is plotted against the uric acid excretion value of control and gouty subjects. Note the three gouty subjects who show both excessive specific activity values and excessive excretion of uric acid. 


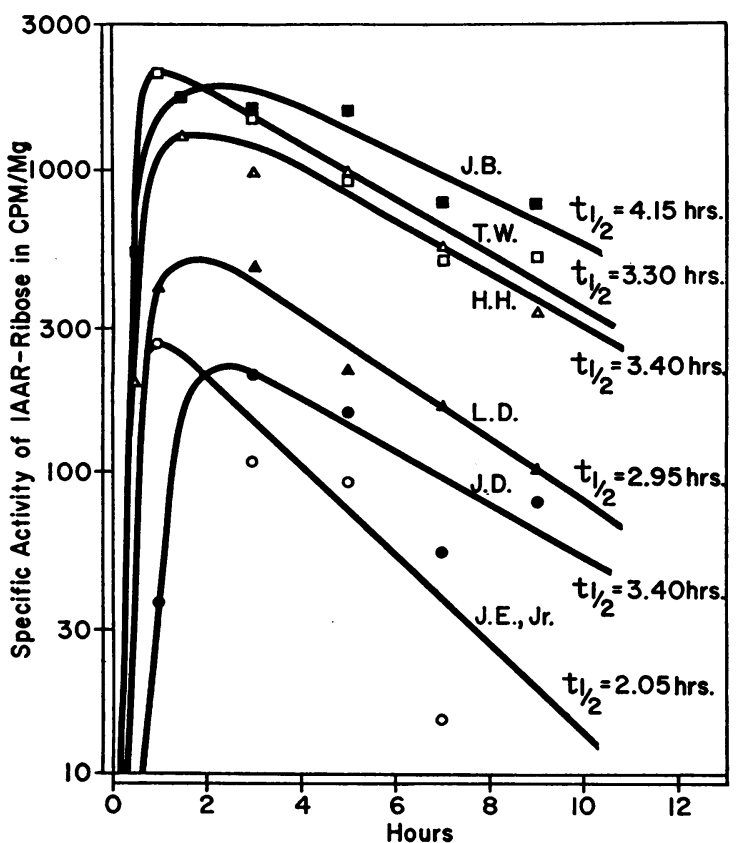

Fig. 5. TIME COURSE OF ENRICHMENT OF THE RIBOSE MOIETY OF IMIDAZOLEACETIC ACID RIBONUCLEOSIDE. The specific activity values of the ribose moiety of IAAR, in successive 2-hour urine samples of control and gouty subjects described in the legend of Figure 3, are plotted on semilogarithmic coordinates. The specific activity decay curves have been drawn and the half-times calculated, chiefly to show that the rates of decline of specific activity values are similar in the overexcretor gouty subjects (J.B., T.W., and H.H.) and the controls (L.D. and J.D.).

tions fall entirely within the control range and the mean values are very similar: controls, 0.038 per cent; gouty subjects with normal urate excretion, 0.035 per cent. In contrast, the incorporation values found in the overexcretor group of gouty patients are clearly elevated and well outside the control range.

The cumulative incorporation of $\mathrm{C}^{14}$ into IAAR was followed in consecutive 2-hour urine samples in two control and four gouty subjects. The gouty subjects included one with normal and three with excessive urinary uric acid excretion. The results are shown in Figure 3. The excessive incorporation of $\mathrm{C}^{\mathbf{1 4}}$ into IAAR in the three overexcretor gouty subjects was marked by an acceleration of initial rate of isotope incorporation, most prominent in the first 4 to 6 hours after administration of glucose $\mathrm{C}^{\mathbf{1 4}}$ and IAA.

Specific activity of the ribose moiety of IAAR. The mean specific activity of ribose in IAAR during the 10-hour experimental period is shown for all subjects in Table I and is plotted as a function of the 24-hour uric acid excretion in Figure 4. Specific activity values in the seven control subjects ranged from 128 to 484 (mean 305) cpm per $\mathrm{mg}$ of ribose; in the 6 gouty subjects with normal uric acid excretion the values ranged from 120 to 402 (mean 268) cpm per $\mathrm{mg}$ of ribose. There was no correlation of specific activity values with uric acid excretion in either group. In contrast, the three gouty patients with excessive uric acid excretion values showed strikingly elevated specific activity values, in keeping with the excessive incorporation of $\mathrm{C}^{14}$ reported above. The values were $950,1,104$, and $1,120 \mathrm{cpm}$ per $\mathrm{mg}$ of ribose.

Specific activity values were obtained in consecutive 2-hour samples of the two control subjects and four gouty patients whose cumulative incorporation data were presented above. These data are shown in Figure 5. Peak enrichment values were attained during the first two hours in the gouty patients and in the two- to four-hour sample in both controls. The maximal value attained in the three overexcretor gouty subjects exceeded those found in control subjects and in the normal excretor gouty subjects by three-fold. However, the half-times of rates of decline in

TABLE II

Repetition of study in gouty overexcretor subject, J.B.

\begin{tabular}{ccccccc}
\hline \hline $\begin{array}{c}\text { Date of } \\
\text { study }\end{array}$ & \multicolumn{2}{c}{ Uric acid } & & $\begin{array}{c}\text { Excretion of } \\
\text { IAAR } \\
\text { Per cent of } \\
\text { administered } \\
\text { IAA }\end{array}$ & $\begin{array}{c}\text { C14 in IAAR- } \\
\text { Per cent of } \\
\text { administered } \\
\text { glucose-U-C14 }\end{array}$ & $\begin{array}{c}\text { Specific } \\
\text { activity } \\
\text { of IAAR }\end{array}$ \\
\cline { 2 - 7 } & Serum & Urine & & & & $\begin{array}{c}\text { cpm } / m g \\
\text { ribose }\end{array}$ \\
$2-29-60$ & $m g \%$ & $m g / 24 h r s$ & & & 0.310 & 1220 \\
$4-24-61$ & 10.8 & 670 & 30.5 & 0.270 & 1209 \\
\hline
\end{tabular}

* Second study conducted without interruption of uricosuric drug; see text. 
specific activity values were comparable in all subjects. Even though the data are insufficient to permit determination of precise half-time values (Figure 5), they were clearly not shorter in the overexcretor gouty group than in the control subjects.

Confirmatory study on gouty overexcretor subject. As a methodologic and biologic check of the abnormal results obtained in the overexcretor group of gouty subjects, the study on J.B., a 45year-old man with severe tophaceous gout, was repeated after a 14-month interval. At the time of the first study he was receiving no drug treatment; at the time of the second he was receiving daily colchicine and sulfinpyrazone and had a serum uric acid value of $2.9 \mathrm{mg}$ per $100 \mathrm{ml}$. The results of the two studies are shown in Table II and are taken to be in satisfactory agreement. Furthermore, in the second study rechromatography of IAAR on paper after elution from Dowex $50-\mathrm{H}^{+}$resin (see Methods) demonstrated conclusively that the highly enriched ribose was in IAAR, and not some other ribose-containing compound. These results also indicate that the turnover of PRPP is not regulated by the serum level of uric acid, nor affected to any major extent by the drugs employed.

\section{DISCUSSION}

The present study demonstrates that gouty subjects who excrete excessive quantities of uric acid in urine also convert a greater fraction of an administered dose of glucose- $U-\mathrm{C}^{14}$ to phosphoribosylpyrophosphate (PRPP) and attain a greater specific activity in PRPP than do control subjects or gouty subjects with normal uric acid excretion values. The data also suggest that gouty overexcretors achieve peak specific activity values in PRPP somewhat earlier than control subjects, but the rates of decline of specific activity values following the maxima are not more rapid, nor are the quantities of imidazoleacetic acid ribonucleoside formed and excreted larger than in control subjects.

The greater specific activity of PRPP signifies that the administered glucose- $\mathrm{C}^{14}$ has undergone less dilution with unlabeled substances in gouty overexcretors than in the other subjects. This could theoretically result from 1) poor mixing of

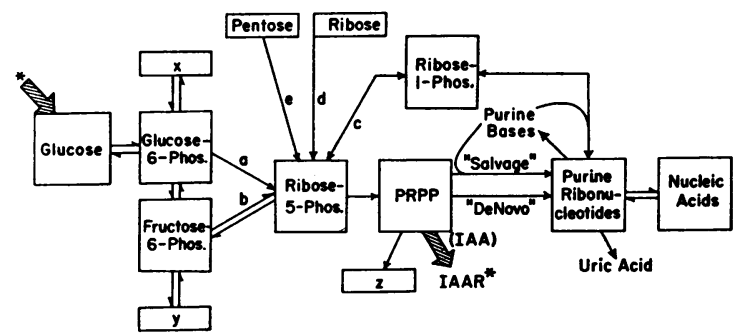

Fig. 6. MOdel of hypothetical Metabolic POOLS AND KNOWN BIOCHEMICAL REACTIONS INFLUENCING ISOTOPIC LABELING OF RIBOSE IN THE PRESENT STUDY. The glucose pool was labeled by oral administration of glucose-U-C $\mathrm{C}^{\mathbf{1 4}}$. The PRPP pool was sampled by oral administration of imidazoleacetic acid, which reacts with PRPP to form the corresponding ribonucleotide and is excreted in urine as imidazoleacetic acid ribonucleoside. Pathways $a, b$, $c, d$, and $e$ represent routes of synthesis of ribose 5-phosphate (see text). Pools $x$ and $y$ represent other metabolic pools in equilibrium with glucose 6-phosphate and fructose 6-phosphate respectively; pool $z$ represents all non-purine ribonucleotide pools to which PRPP may contribute, some of which may also be sources, ultimately, of ribose 1-phosphate.

glucose $\mathrm{C}^{14}$ within the glucose pool, 2) an unusually small pool of glucose, ribose 5-phosphate, or of any intermediate compound, or 3) an increase in the fraction of PRPP derived from glucose in comparison with the fraction derived from other less highly labeled precursors.

The reaction model shown in Figure 6 has been constructed on the basis of known biochemical reactions of pertinence to the present study. It should be recalled that gouty overexcretors regularly show enhanced incorporation of labeled precursors into uric acid, whether the precursor is ammonium- $\mathrm{N}^{15}$ (12), glycine- $\mathrm{N}^{15}$ (5) or $\mathrm{C}^{14}$ $(6,7,11,30)$, formate- $C^{14}(8)$, or 5 -amino-4imidazole-carboxamide- $\mathrm{C}^{14}$ (38). Thus, an increased activity of purine synthesis de novo is well established in this type of gouty subject.

The increased utilization of all reactants of an unbranched biosynthetic sequence is a necessary corollary of the increased utilization of any one, if the laws of stoichiometry are not to be violated. Hence, an increased utilization of PRPP would be anticipated if PRPP is indeed the sole precursor of phosphoribosylamine, the obligatory antecedent of purine ribonucleotides. This study was designed to test this point and, if possible, to assess the compensatory participation of alternative path- 
ways for synthesis of ribose 5-phosphate, the immediate precursor of PRPP.

As shown in Figure 6, ribose 5-phosphate has five known pathways of synthesis: $a$ represents the phosphogluconic acid oxidation pathway by which glucose 6-phosphate is irreversibly converted to ribose 5 -phosphate; $b$ represents the fructose 6 -phosphate cleavage pathway via which fructose 6-phosphate and ribose 5-phosphate may be interconverted; $c$ represents the phosphoribomutase reaction whereby ribose-1-phosphate, released from ribonucleosides by action of purine and pyrimidine nucleoside phosphorylases, is reversibly converted to ribose 5-phosphate; $d$ represents the ribokinase reaction whereby free ribose, released by action of phosphatases on ribose phosphates, is phosphorylated to form ribose 5-phosphate; $e$ represents a number of potential pathways, probably of trivial quantitative importance under normal circumstances, by which other pentoses may be converted to D-ribulose 5-phosphate and thence to ribose 5-phosphate (39).

Increased utilization of PRPP in purine synthesis will lead to an increased rate of renewal of PRPP from ribose 5-phosphate and subsequently of ribose 5-phosphate via one or more of its biosynthetic pathways. If the glucose 6-phosphate pool is preferentially labeled by administration of glucose $\mathrm{C}^{14}$, the peak specific activity of ribose 5-phosphate will reflect the quanta of ribose 5-phosphate arising via $a$ with respect to $a+b+$ $c+d+e$, or if glucose 6-phosphate and fructose 6-phosphate rapidly equilibrate, then the specific activity of ribose 5-phosphate will reflect the quanta of ribose 5-phosphate arising via $a+b$ with respect to $a+b+c+d+e$. Pathways $c$ and $d$ cannot contribute isotope to ribose 5 -phosphate unless ribose 5-phosphate first becomes labeled via $a$ or $b$ and is then hydrolyzed to free ribose, or is reversibly converted to ribose 1-phosphate via phosphoribomutase, or converted to ribose 1-phosphate via PRPP, and ribonucleotide and ribonucleoside intermediates.

The results obtained in the gouty overexcretor patients are best explained as consequences of increases in the rate of operation of the pathway of synthesis of purine ribonucleotides de novo, with an increase, pari passu, in the rates of synthesis of PRPP, and of ribose 5-phosphate, from glucose 6-phosphate, via either the phosphogluconic acid oxidation pathway or the fructose 6-phosphate cleavage pathway, or both. The data exclude at least one alternative consideration: a simple reduction of pool size of ribose 5-phosphate would give rise to a higher than normal peak specific activity value but would also result in an accelerated rate of decline of specific activity values. Poor mixing of glucose $\mathrm{C}^{14}$ within the glucose pool, or a small mixing pool of any intermediate prior to ribose 5-phosphate, is unlikely to have occurred only in the three gouty hyperexcretor patients, and in one of them twice at a 14-month interval, but it cannot rigorously be excluded. Nor can a disproportion of relative contributions of pathways $a$ to $e$ (e.g., a markedly reduced contribution of $c$ ) be excluded as a theoretical cause of increased labeling of ribose 5-phosphate, but such perturbations appear rather implausible.

The accelerated synthesis of PRPP from glucose, set forth as the best interpretation of the data, is consistent with a number of possible mechanisms for the metabolic aberration of gout and is indeed a necessary consequence of any of them. These possibilities include : 1) a defect of nitrogen metabolism by which an increased quantity of one or more amino acids is shunted into purine synthesis $(12,40,41) ; 2)$ a disturbance of the feedback control mechanism governing activity of PRPP-amidotransferase leading to a primary excess of synthesis of purines; 3 ) a catabolic defect causing a persistent "leak" of inosinic acid, for example, toward purine bases and uric acid, and a secondary increase in purine synthesis; or 4) an increase in turnover of a metabolically active nucleic acid component. A primary increase in activity of the phosphogluconic acid oxidation pathway with resultant oversynthesis of PRPP might also be entertained, but such a defect, if responsible for the abnormalities of PRPP labeling reported herein, would have been anticipated to yield concomitant increases in the quantities of imidazoleacetic acid riboside in urine, and such were not found.

The arguments presented above rest upon the assumption that the pool of PRPP sampled in synthesis of imidazoleacetic acid ribonucleotide is identical with, or in rapid equilibrium with, the pool of PRPP available to PRPP-amidotransferase in the synthesis of phosphoribosylamine. Since an accelerated turnover of PRPP was dem- 
onstrated in types of patients presenting abundant independent evidence for overproduction of $\mathrm{pu}$ rines de novo, this assumption appears to be a reasonable one. It is anticipated that the enhanced labeling of PRPP would also be reflected in other products synthesized from PRPP, e.g., diphosphopyridine nucleotide (42), orotidylic acid, the first ribonucleotide intermediate of pyrimidine synthesis (43), and purine ribonucleotides formed by direct condensation of purine bases released by degradative reactions with PRPP (44). All of these reaction sequences proceed actively in liver and might also give information on the turnover of PRPP if they derived their ribose moieties from the same intracellular pools of PRPP and if they could be sampled simultaneously with IAAR. As pointed out above, urinary uridine was unlabeled in the urine sample obtained 0 to 10 hours after administration of glucose $\mathrm{C}^{14}$ and therefore presumably represents uridine synthesized at an earlier time, perhaps arising from ribonucleic acid catabolism. Thus, no information of the degree to which the increased labeling of PRPP observed in overexcretor gouty subjects was reflected in other ribose containing compounds was obtained.

Since PRPP is involved in a number of reactions, a question arises whether a block in one sequence might provide an excess of PRPP for utilization in other sequences and whether overproduction of purines might arise as one consequence of such a block (45). Although this might be a theoretical possibility, a simple reapportionment of PRPP among its various fates would not lead to an increase of PRPP labeling and hence seems excluded as a consideration in the gouty overexcretor subject.

The normal labeling of PRPP in the group of gouty patients with normal uric acid excretion values again raises the question of heterogeneity of the gouty defect. It seems unlikely from the data of Figure 2 and Figure 4 that PRPP turnover (and by implication uric acid production) is a continuous variable in the gouty population; despite the limited number of patients studied, the two groups give every appearance of being discontinuous. The normal specific activity values of PRPP in this group, in whom other techniques of study frequently show abnormalities of isotope incorporation or distribution in uric acid, have several possible interpretations. 1) The study of
PRPP turnover may be inherently too gross at the technical or biological level to reveal minor differences which might nevertheless be of metabolic importance. 2) PRPP turnover may actually be accelerated in this group, but the resultant increase in synthesis of the precursor, ribose 5-phosphate, may involve pathways $a, b, c, d$, and $e$ in a balanced way so that the fraction of ribose 5-phosphate arising from glucose 6-phosphate is unchanged, and hence the specific activity of ribose 5-phosphate and PRPP is unchanged. 3) $\mathrm{Pu}$ rine production may not be accelerated in these particular patients, and renal factors may be responsible for hyperuricemia. Independent incorporation studies were not done in this group; in only one patient (J.E., Jr.) were clearance studies performed, and low urate/inulin clearance ratios were found in him (29). Recent studies in other laboratories have refocused attention on the role of the kidney in the hyperuricemia of gout (46). There is evidence that both overproduction and underexcretion of uric acid may be involved (47) and that these mechanisms are not mutually exclusive but may operate in concert in certain patients.

\section{SUM MARY}

1. The turnover of $5 \alpha$-phosphoribosyl-1-pyrophosphate (PRPP), a key early intermediate in purine synthesis, has been studied in control and gouty subjects by an indirect approach involving administration of glucose- $\mathrm{U}-\mathrm{C}^{14}$ to label the ribose moiety of PRPP and imidazoleacetic acid to sample PRPP in the formation of its ribonucleotide derivative. Urinary imidazoleacetic acid ribonucleoside (IAAR) was isolated and studied.

2. The incorporation of $\mathrm{C}^{14}$ into IAAR and the specific activity of IAAR were three times greater in three gouty subjects who overexcreted uric acid than in control subjects or in gouty subjects with normal urinary excretions of uric acid.

3. These results indicate that the turnover of PRPP is accelerated in the type of gouty patient in whom other studies give independent evidence for overproduction of uric acid. They further suggest that the accelerated turnover of PRPP is accompanied by an increase in rate of renewal of PRPP from glucose 6-phosphate.

4. Normal isotopic labeling of IAAR was found in gouty persons with normal uric acid excretion, 
and this may signify that PRPP turnover is not accelerated in these patients or that this method of study is inadequate to detect increases of turnover of subtle degree.

\section{ACKNOWLEDGMENT}

The authors are indebted to Dr. Norman Bauman for helpful discussions in the preparation of the reaction model and a mathematical evaluation of the fit of the data.

\section{REFERENCES}

1. Jones, O. W., and Wyngaarden, J. B. Studies on turnover of "active ribose" in hyperuricemia. Clin. Res. 1960, 8, 58.

2. Wyngaarden, J. B., Jones, O. W., and Ashton, D. M. Increased turnover of phosphoribosylpyrophosphate, a purine nucleotide precursor, in certain gouty subjects. Atti del $\mathrm{X}$ Congresso della Lege Internationale contro il Reumatismo, 1961, vol. 1, p. 249.

3. Benedict, J. D., Forsham, P. H., and Stetten, D., Jr. The metabolism of uric acid in the normal and gouty human studied with the aid of isotopic uric acid. J. biol. Chem. 1949, 181, 183.

4. Sorensen, L. B. Degradation of uric acid in man. Metabolism 1959, 8, 687.

5. Benedict, J. D., Yü, T. F., Bien, E. J., Gutman, A. B., and Stetten, D., Jr. A further study of the utilization of dietary glycine nitrogen for uric acid synthesis in gout. J. clin. Invest. 1953, 32, 775.

6. Wyngaarden, J. B. Normal glycine-C $\mathrm{C}^{14}$ incorporation into uric acid in primary gout. Metabolism 1958, 7, 374.

7. Gutman, A. B., Yü, T. F., Black, H., Yalow, R. S., and Berson, S. A. Incorporation of glycine-1- $\mathrm{C}^{\mathbf{1 4}}$, glycine-2- $\mathrm{C}^{14}$, and glycine- $\mathrm{N}^{15}$ into uric acid in normal and gouty subjects. Amer. J. Med. 1958, 25, 917.

8. Spilman, E. L. Uric acid synthesis in the nongouty and gouty human. Fed. Proc. 1954, 13, 302.

9. Gutman, A. B., and Yü, T. F. Renal function in gout with a commentary on the renal regulation of urate excretion, and the role of the kidney in the pathogenesis of gout. Amer. J. Med. 1957, 23, 600.

10. Wyngaarden, J. B. Gout in The Metabolic Basis of Inherited Disease, J. B. Stanbury, J. B. Wyngaarden, and D. S. Fredrickson, Eds. New York, McGraw-Hill, 1960, p. 679.

11. Seegmiller, J. E., Grayzel, A. I., Laster, L., and Liddle, L. Uric acid production in gout. J. clin. Invest. 1961, 40, 1304.

12. Gutman, A. B., Yü, T. F., Adler, M., and Javitt, N. B. Intramolecular distribution of uric acid $\mathrm{N}^{15}$ after administration of glycine- $\mathrm{N}^{15}$ and ammonium- $\mathrm{N}^{15}$ chloride to gouty and nongouty subjects. J. clin. Invest. 1962, 41, 623.
13. Wyngaarden, J. B., Blair, A. E., and Hilley, L. On the mechanism of overproduction of uric acid in patients with primary gout. J. clin. Invest. 1958, 37, 579.

14. Wyngaarden, J. B., and Ashton, D. M. The regulation of activity of phosphoribosylpyrophosphate amidotransferase by purine ribonucleotides: a potential feedback control of purine biosynthesis. J. biol. Chem. 1959, 234, 1492.

15. Hartman, S. C., and Buchanan, J. M. Biosynthesis of the purines. XXI. 5-Phosphoribosylpyrophosphate amidotransferase. J. biol. Chem. 1958, 233, 451.

16. Nierlich, D. P., and Magasanik, B. Alternative first steps of purine biosynthesis. J. biol. Chem. 1961, 236, PC32.

17. Nierlich, D. P. Personal communication, July, 1962.

18. Tabor, H., and Hayaishi, $O$. The excretion of imidazoleacetic acid riboside following the administration of imidazoleacetic acid or histamine to rats. J. Amer. chem. Soc. 1955, 77, 505.

19. Hiatt, H. H. Studies of ribose metabolism. VI. Pathways of ribose synthesis in man. J. clin. Invest. 1958, 37, 1461.

20. Crowley, G. M. Enzymatic synthesis of imidazoleacetic acid ribotide. Fed. Proc. 1960, 19, 309.

21. Hiatt, H. H. Studies of ribose metabolism. II. A method for the study of ribose synthesis in vivo. J. biol. Chem. 1957, 229, 725.

22. Bauer, $H$., and Tabor, $H$. The synthesis of imidazoleacetic acid. Biochem. Prep. 1957, 5, 97.

23. Mehler, A. H., Tabor, H., and Bauer, H. The oxidation of histamine to imidazoleacetic acid in vivo. J. biol. Chem. 1952, 197, 475.

24. Takagi, Y., and Horecker, B. L. Purification and properties of a bacterial riboside hydrolase. J. biol. Chem. 1957, 225, 77.

25. Wyngaarden, J. B. 2,6-Diaminopurine as substrate and inhibitor of xanthine oxidase. J. biol. Chem. 1957, 224, 453.

26. Tiselius, A., Hjertén, S., and Levin, Ö. Protein chromatography on calcium phosphate columns. Arch. Biochem. 1956, 65, 132.

27. Carey, F. G., Fridovich, I., and Handler, P. Preparation of several forms of xanthine oxidase by enzymic proteolysis. Biochim. biophys. Acta 1961, 53, 443.

28. Praetorius, E. An enzymatic method for the determination of uric acid by ultraviolet spectrophotometry. Scand. J. clin. Lab. Invest. 1949, 1, 222.

29. Wyngaarden, J. B., and Jones, O. W. The pathogenesis of gout. Med. Clin. N. Amer. 1961, 45, 1241.

30. Wyngaarden, J. B. Overproduction of uric acid as the cause of hyperuricemia in primary gout. $\mathrm{J}$. clin. Invest. 1957, 36, 1508.

31. Grayzel, A. I., Liddle, L., and Seegmiller, J. E. Diagnostic significance of hyperuricemia in arthritis. New Engl. J. Med. 1961, 265, 763. 
32. Albaum, H. G., and Umbreit, W. W. Differentiation between ribose-3-phosphate and ribose-5-phosphate by means of the orcinol-pentose reaction. J. biol. Chem. 1947, 167, 369.

33. Hayes, F. N., Rogers, B. S., and Sanders, P. C. Importance of solvent in liquid scintillators. $\mathrm{Nu}$ cleonics 1955, 13, 46.

34. Peterson, R. E. The application of tritium to the assay of steroids in biological extracts. Proc. of the Symposium on Advances in Tracer Applications of Tritium, New York, October 31, 1958, p. 16.

35. Smith, I. Chromatographic and Electrophoretic Techniques. New York, Interscience, 1960, vol. 1, p. 252.

36. Hunter, G. A new test for ergothioneine upon which is based a method for its estimation in simple solution and in blood-filtrates. Biochem. J. 1928, 22, 4.

37. Partridge, S. M. Aniline hydrogen phthalate as a spraying reagent for chromatography of sugars. Nature 1949, 164, 443.

38. Seegmiller, J. E., Laster, L., and Stetten, D., Jr. Uric acid formation in patients with gout. The incorporation of 4-amino-5-imidazolecarboxamide$C^{13}$ into uric acid. Ninth International Congress on Rheumatic Diseases, programme, 1957, vol. 2, p. 207.

39. Wyngaarden, J. B., Segal, S., and Foley, J. B. Physiological disposition and metabolic fate of infused pentoses in man. J. clin. Invest. 1957, 36, 1395.
40. Benedict, J. D., Roche, M., Yü, T. F., Bien, E. J., Gutman, A. B., and Stetten, D., Jr. Incorporation of glycine nitrogen into uric acid in normal and gouty man. Metabolism 1952, 1, 3.

41. Zöllner, N. Inborn disorders of metabolism. J. chron. Dis. 1959, 10, 6.

42. Preiss, J., and Handler, P. Biosynthesis of diphosphopyridine nucleotide. II. Enzymatic aspects. J. biol. Chem. 1958, 233, 493.

43. Lieberman, I., Kornberg, A., and Simms, E. S. Enzymatic synthesis of pyrimidine nucleotides, orotidine-5'-phosphate and uridine-5'-phosphate. J. biol. Chem. 1955, 215, 403.

44. Kornberg, A. Pathways of enzymatic synthesis of nucleotides and polynucleotides in The Chemical Basis of Heredity, W. D. McElroy and B. Glass, Eds. Baltimore, Johns Hopkins Press, 1957, p. 579.

45. Smith, L. H., Jr., Sullivan, M., and Huguley, C. M., Jr. Pyrimidine metabolism in man. IV. The enzymatic defect of orotic aciduria. J. clin. Invest. 1961, 40, 656.

46. Lathem, W., and Rodnan, G. P. ' Uric acid excretion in gout: evidence of an abnormality in renal transport. J. clin. Invest. (abstract) 1961, 40, 1056.

47. Wyngaarden, J. B. On the dual etiology of hyperuricemia in primary gout. Arth. Rheum. 1960, 3, 414. 